\title{
COMPARISON OF DIFFERENT AGENTS FOR SURFACE TREATMENT OF ALUMINIUM BY ELECTROCHEMICAL OXIDATION
}

\author{
Vít ZÁLIŠ, ${ }^{2}$ Jiří BÁRTA \\ ${ }^{1}$ Czech Aerospace Research Centre, Prague, Czech Republic, EU, zalis@vzlu.cz \\ ${ }^{2}$ Czech Aerospace Research Centre, Prague, Czech Republic, EU, jiri.barta@vzlu.cz
}

https://doi.org/10.37904/metal.2020.3563

\begin{abstract}
The aim of this study is to compare the corrosion resistance of anodic oxidation coatings on Al2024 alloy. Due to its composition with a high content of alloying elements (mainly $\mathrm{Cu}$ ), anodization of this alloy is one of the difficult ones compared to most other alloys or pure aluminium. In this study, the Cr6+ free baths were used for anodic oxidation of the Al 2024 alloy because of high toxicity of $\mathrm{Cr} 6+$ based baths, which are legislatively restricted nowadays. One of the possible ways is the use of mixtures of organic and inorganic acids and various additives (such as e.g. tartaric, citric, glycolic, malonic acid etc.). It is also possible to use commercial products as additives for sulfuric acid anodization (SAA). In this study, the samples were anodized in four types of anodizing baths and subsequently sealed in boiling water. The surface and metallographic specimen were observed by optical microscope and scanning electron microscope (SEM). The thickness was measured using the eddy current method. The anti-corrosion properties of the layers were verified using the accelerated Machu test.
\end{abstract}

Keywords: Aluminium alloy, anodization, additive, organic acid, corrosion

\section{INTRODUCTION}

Aluminium alloys are a widely used construction material in the aerospace, automotive, building industry etc. Aluminium and its alloys are prone to corrosion, they need to be effectively protected. Anodic oxidation is an electrochemical process in which a porous layer of $\mathrm{Al} 2 \mathrm{O} 3$ is formed on the surface of aluminium. After subsequent sealing, a barrier is formed between the metal and the external environment [1].

One of the oldest processes is anodic oxidation in chromic acid [2]. The use of this bath provides excellent corrosion protection with a low effect on the fatigue properties of alloys. However, Cr6+ containing compounds are toxic and harmful to health, therefore the use of such products is restricted/prohibited by law. For this reason, it is appropriate to replace the anodizing bath containing Cr6+ with a suitable environmentally friendly product that will achieve the same or at least similar results [3].

One of the possible solutions is to use the mixture of tartaric and sulfuric acid. It is also possible to apply salts of transition elements as an additive [4]. Another possibility is to use commercially available additives, which usually contain different amounts of various organic acids and other components. These commercial additives promise the formation of compact layers without extensive cooling demand and, also promise extended bath life due to the high tolerance to the aluminium content.

\section{EXPERIMENTAL}

For the reasons mentioned above, this study deals with anodic oxidation in tartaric acid (TSAA), in which the effect of temperature and applied current voltage on the thickness and homogeneity of the coatings was observed. Coating thickness is one of the important factors influencing corrosion resistance [5]. In addition, 
two commercially available additives were tested in this study. The first from Alufinish GmbH \& Co. KG (Alfinox 510) and the second from Ekochem ppú s. r. o. (Rogal 3).

Al 2024 alloy was chosen as the test material. Namely it was $Q$ panels from Labimex CZ s. $r$. o. The panels were cut to dimensions $50 \mathrm{~mm} \times 71 \mathrm{~mm} \times 1 \mathrm{~mm}$. Prior to the process itself, the samples were degreased in an ultrasonic bath in a solution of sodium hydroxide, carbonate and dodecyl sulphate at $50{ }^{\circ} \mathrm{C}$ for 8 minutes. This was followed by alkaline pickling in $\mathrm{NaOH}$ solution $(60 \mathrm{~g} / \mathrm{l})$ at $50^{\circ} \mathrm{C}$ for 1 minute. Finally, the samples were activated in diluted $\mathrm{HNO} 3$ solution for $30 \mathrm{~s}$ and then anodized. The sample was naturally connected as an anode and the cathode used in this study was stainless steel. The anodizing bath was stirred during the experiments. After each step, the sample was washed with a stream of DEMI water and left in a rinsing bath for at least 2 minutes. Subsequently, the resulting coatings on the samples were sealed in boiling DEMI water $\left(97^{\circ} \mathrm{C}\right)$ for at least 30 minutes.

The following four baths were used in the experiment. Bath number $1(30 \mathrm{~g} / \mathrm{l} \mathrm{H} 2 \mathrm{SO} 4+60 \mathrm{~g} / \mathrm{C} 4 \mathrm{H} 6 \mathrm{O} 6)$, bath number 2 (30 g/l H2SO4 + $60 \mathrm{~g} / \mathrm{l} \mathrm{C4H6O6} \mathrm{+} \mathrm{additive),} \mathrm{bath} \mathrm{number} 3(140 \mathrm{~g} / \mathrm{l} \mathrm{H} 2 \mathrm{SO} 4+30 \mathrm{~g} / \mathrm{l} \mathrm{Rogal} 3 \mathrm{~A}+30$ $\mathrm{g} / \mathrm{l}$ Rogal 3B $+1 \mathrm{ml} / \mathrm{l}$ Rogal 3.1) and bath number 4 (140 g/l H2SO4 + $25 \mathrm{~g} /$ / Alfinox 510). For commercial additives, the range of parameters such as temperature, voltage and current density is fixed in the technical data sheets. In the tartaric acid experiments, the temperature and intensity of the applied current voltage were experimented with, thus achieving different thicknesses and quality of the resulting layers.

The thickness of the layers was measured with a thickness gauge (Surfix - PHYNIX GmbH \& Co.KG) on the principle of eddy currents. Furthermore, metallography samples were prepared, on which the measurement results were verified.

Use of organic acids is based on increasing the conductivity of the electrolyte. The addition of organic acid does not increase aggressiveness of acid solution. Then the tendency to re-dissolving of anodic layer is not affected. In the case of bath number 2, salt of transition metal was added as an additive. Salts of transition metals have been found to mitigate the effects of anodizing by-products. An assumption for this effect is a sufficient positive or negative charge (ability to be easily oxidized or reduced) [4].

\subsection{Tartaric - sulfuric acid anodization (TSAA)}

Five samples underwent the experiment. Different current densities were applied, and the exposure time ranged from 45 minutes to 80 minutes. The exact parameters are summarized in Table 1.

Table 1 TSAA (parameters and coating thickness)

\begin{tabular}{|c|c|c|c|c|c|}
\hline Sample & A 55x & B 32x & C 36x & D 33x & E 37x \\
\hline $\begin{array}{l}\text { Current density } \\
\text { [A/dm2] }\end{array}$ & 0.7 & 1 & 0.6 & 1.5 & 0.8 \\
\hline $\begin{array}{c}\text { Temperature } \\
{\left[{ }^{\circ} \mathrm{C}\right]}\end{array}$ & 38 & 38 & 30 & 38 & 32 \\
\hline Time [min] & 45 & 45 & 80 & 45 & 60 \\
\hline $\begin{array}{c}\text { Thickness } \\
\text { (average) }[\mu \mathrm{m}]\end{array}$ & 5.4 & 9.9 & 11.5 & 11.4 & 10.8 \\
\hline Effectivity [\%] & 33 & 42 & 43 & 38 & 44 \\
\hline
\end{tabular}

\subsection{Tartaric - sulfuric acid anodization with additive}

Five samples underwent the experiment. Different current densities were applied, and the exposure time ranged from 50 minutes to 120 minutes. The exact parameters are summarized in Table 2. 
Table 2 TSAA + additive (parameters and coating thickness)

\begin{tabular}{|c|c|c|c|c|c|}
\hline Sample & $F 38 x$ & G 47x & H 48x & $152 x$ & $\mathrm{~J} 54 \mathrm{x}$ \\
\hline $\begin{array}{c}\text { Current density } \\
{[\mathrm{A} / \mathrm{dm} 2]}\end{array}$ & 0.8 & 1 & 0.9 & 1.5 & 1.7 \\
\hline Temperature $\left[{ }^{\circ} \mathrm{C}\right]$ & 33 & 38 & 33 & 40 & 40 \\
\hline Time [min] & 50 & 50 & 120 & 50 & 50 \\
\hline $\begin{array}{c}\text { Thickness } \\
\text { (average) }[\mu \mathrm{m}]\end{array}$ & 4.1 & 6.0 & 9.7 & 8.4 & 7.7 \\
\hline Effectivity [\%] & 37 & 46 & 33 & 39 & 31 \\
\hline
\end{tabular}

\subsection{Sulphuric acid anodization with Rogal 3}

Two samples underwent the experiment. Concentration of electrolyte was set as provided in technical sheet. Parameters of anodization are summarized in Table 3. It should be noted, that both solid parts of Rogal 3 are quite difficult to dissolve.

Table 3 SAA with Rogal 3

\begin{tabular}{|c|c|c|}
\hline Sample & $\mathrm{K} 2 \mathrm{x}$ & $L 3 x$ \\
\hline Current density [A/dm2] & 2.4 & 3.4 \\
\hline Temperature $\left[{ }^{\circ} \mathrm{C}\right]$ & 26 & 27 \\
\hline Time [min] & 50 & 50 \\
\hline Thickness (average) $[\mu \mathrm{m}]$ & 11.2 & 14.5 \\
\hline Effectivity [\%] & 36 & 32 \\
\hline
\end{tabular}

Sulphuric acid with Alfinox 510

There were 2 specimens subjected to the experiment. Concentration of electrolyte was set as provided in technical sheet. Parameters of anodization are summarized in Table 4. The advantage of Alfinox 510 is its supplied form - a liquid solution eliminating the solubility problem with Rogal 3.

Table 4 SAA with Alfinox 510

\begin{tabular}{|c|c|c|}
\hline Sample & M 4x & N $5 x$ \\
\hline Current density [A/dm2] & 1.7 & 2.4 \\
\hline Temperature $\left[{ }^{\circ} \mathrm{C}\right]$ & 25 & 25 \\
\hline Time [min] & 50 & 50 \\
\hline Thickness (average) [ $\mu \mathrm{m}]$ & 9.4 & 11.5 \\
\hline Effectivity [\%] & 42 & 37 \\
\hline
\end{tabular}

\section{RESULTS AND DISCUSSION}

\subsection{Thickness of anodized layer, metallographic and SEM}

The thickness of coatings was measured by thickness gauge by PHYNIX - Surfix. Subsequently, the thickness was measured from a metallographic microgram (Figure 1). Results confirmed accuracy of non-destructive measurement method.

The thickness of the obtained layers ranged from $5.4 \mu \mathrm{m}$ to $10.8 \mu \mathrm{m}$ in the case of TSAA and $4.1 \mu \mathrm{m}$ to 9.7 $\mu \mathrm{m}$ in the case of TSAA with additive, according to anodizing parameters. The thickness of those obtained 
from sulfuric acid with commercial additives was in range of $9,4 \mu \mathrm{m}$ to $14,5 \mu \mathrm{m}$ also depending on specific parameters.

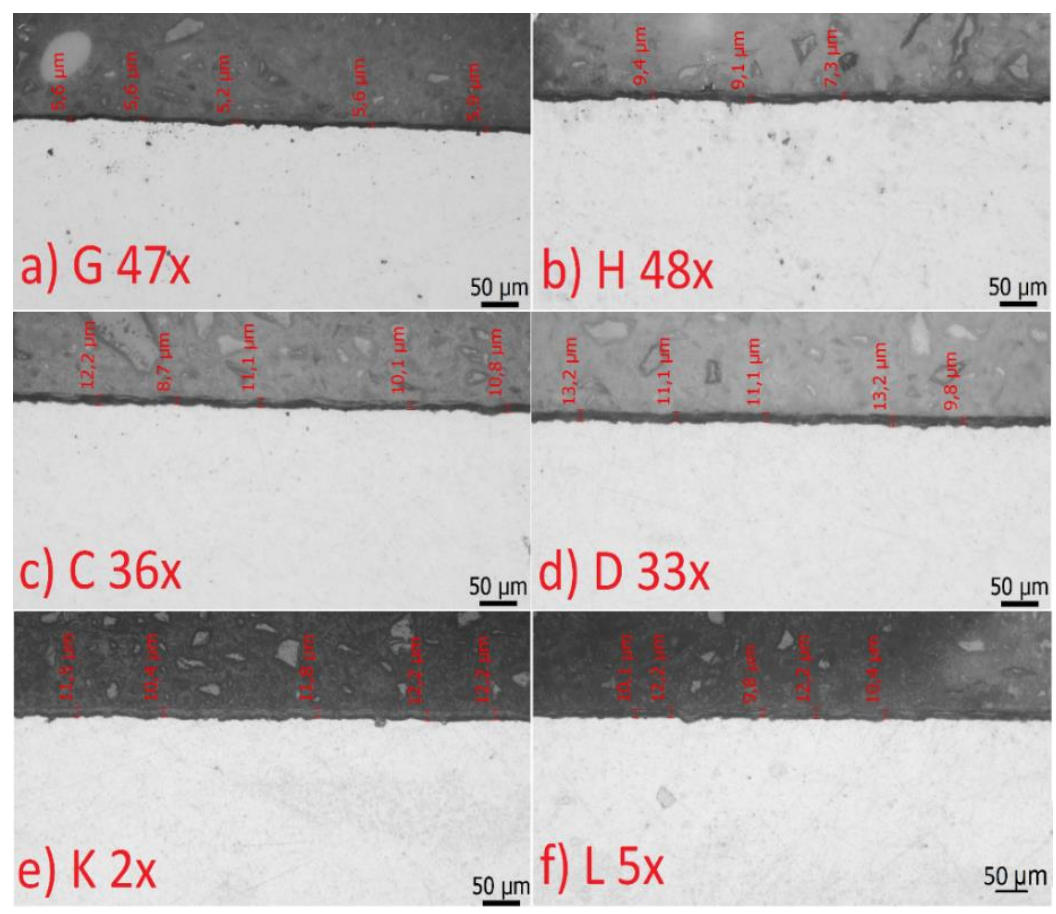

Figure 1 Cross section of selected samples

From the obtained data, it is clear, that with increasing current density, the thickness of the coating also increases. The same correlation can be observed in the case of changes in electrolyte temperature, while anodizing in TSAA baths. With increasing temperature, the conductivity of the electrolyte increases and, despite the effect of back-dissolution, thicker layers form in all TSAA tested electrolytes. However, too long an exposure time is not energy efficient and the growth of the layer is very slow, as can be deduced from the thickness of the layer formed in the TSAA with the additive after 120 minutes of exposure.

\subsection{Accelerated corrosion Machu test}

The species were subjected to accelerated corrosion Machu test for $48 \mathrm{~h}$ according to Qualicoat and QIB specifications. After the first 24 hours, the samples were put out and their condition was documented (Figure 1, Figure 2). Then $5 \mathrm{ml} / \mathrm{l}$ of a $30 \%$ hydrogen peroxide was added to the test solution and the samples were left in the test for another $24 \mathrm{~h}$ (Figure 1, Figure 2). The corrosion rate was evaluated by ČSN EN ISO 10289 (Table 5). In this standard, samples are evaluated on a scale of 1 to 10 according to the percentage area of corrosion.

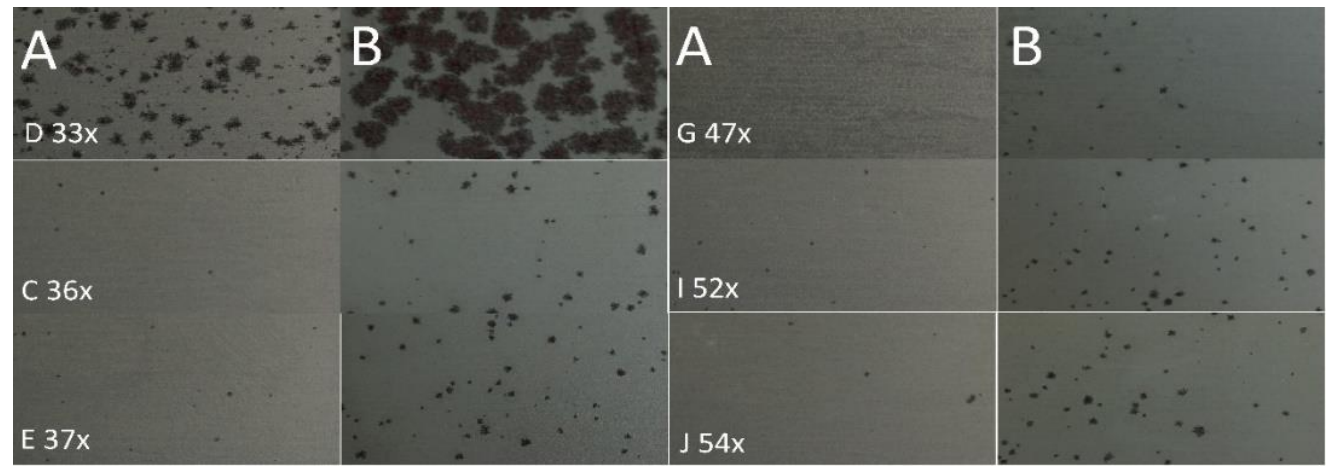

Figure 2 First series of samples after $24 \mathrm{~h}(\mathrm{~A})$ respectively $48 \mathrm{H}$ (B) exposition in Machu test 


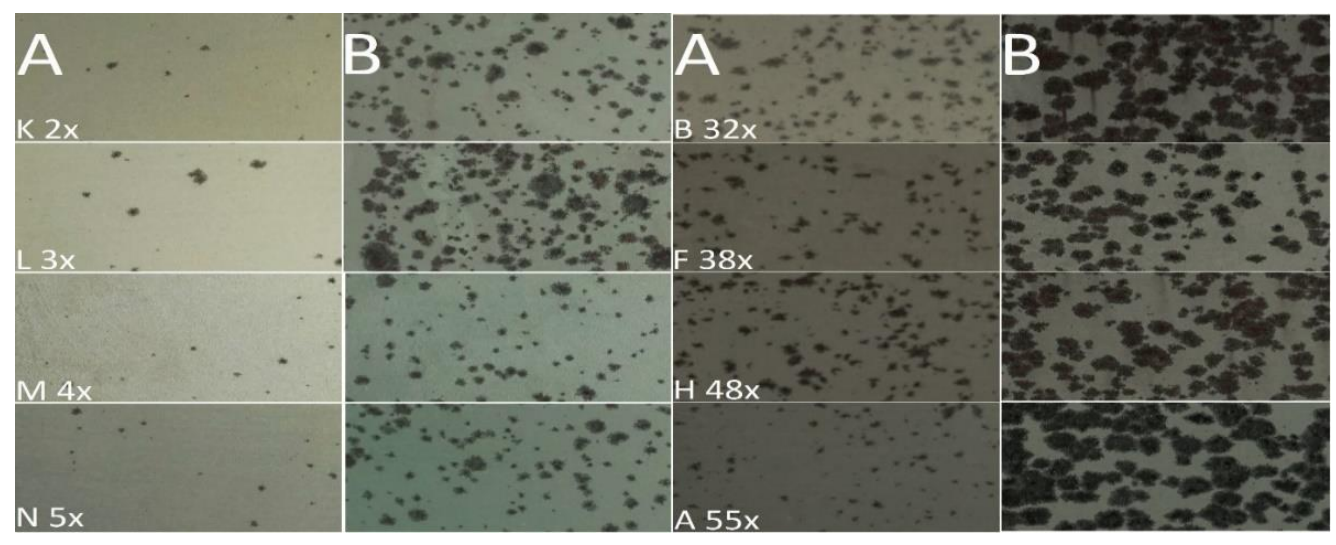

Figure 3 Second series of samples $24 \mathrm{~h}(\mathrm{~A})$ respectively $48 \mathrm{H}(\mathrm{B})$ exposition in Machu test

Table 5 Evaluation of corrosion machu test

\begin{tabular}{|c|c|c|c|}
\hline \multirow{2}{*}{ Bath } & \multirow{2}{*}{ Sample } & \multicolumn{2}{|c|}{ Corrosion rate (ISO 10289) } \\
\cline { 2 - 4 } & & $\mathbf{2 4} \mathbf{h}$ & $\mathbf{4 8} \mathbf{~}$ \\
\hline \multirow{4}{*}{ TSAA } & A 55x & 5 & 1 \\
\cline { 2 - 4 } & B 32x & 4 & 1 \\
\cline { 2 - 4 } & C 36x & 9 & 6,5 \\
\cline { 2 - 4 } & D 33x & 3 & 1 \\
\cline { 2 - 4 } & E 37x & 9 & 5 \\
\hline \multirow{5}{*}{ TSAA + additive } & F 38x & 4 & 2,5 \\
\cline { 2 - 4 } & G 47x & 10 & 8 \\
\cline { 2 - 4 } & H 48x & 4 & 2 \\
\cline { 2 - 4 } & I 52x & 9 & 6,5 \\
\cline { 2 - 4 } & J 54x & 9 & 6 \\
\hline \multirow{3}{*}{ Rogal 3 } & K 2x & 8,5 & 4 \\
\hline \multirow{2}{*}{ Alfinox 510 } & I 3x & 7 & 3,5 \\
\hline & M 4x & 9 & 4,5 \\
\hline
\end{tabular}

\section{CONCLUSION}

Performed tests results conclude that the thickness of the anodic coating itself is not an only factor influencing the corrosion resistance of Al 2024 aluminum alloy. The best result was obtained with $6 \mu \mathrm{m}$ layer (G 47x), while the worst result was found for the sample with a layer of $11.4 \mu \mathrm{m}$ (D 33x). There was no corrosion on sample G $47 \mathrm{x}$ after $24 \mathrm{~h}$ of exposure. However, after 48 hours of exposure, it was possible to observe corrosion on about $0.25 \%$ of the sample area (grade 8 according to ČSN EN ISO 10289). Very good results could be observed for all samples treated in anodizing baths in the presence of commercial additives. The exception was the sample $L 3 x$ with the thickest anodic layer.

\section{ACKNOWLEDGEMENTS}

This result was achieveded with the help of institutional funding of the Czech Ministry of Industry and Trade in the programme dedicated to the development of research organizations. 


\section{REFERENCES}

[1] TAWAKKAL, M. I.; A KORDA, A. Effect of Potential on Corrosion Behavior of Tartaricsulphuric Acid Anodized 7075 T6 Aluminum Alloys. Journal of Physics: Conference Series [Online] 2019.

https://iopscience.iop.org/article/10.1088/1742-6596/1204/1/012038/pdf (accessed March 25, 2020).

[2] BENGOUGH, G.D.; STUART, J.M. Improved process of protecting surfaces of aluminum and aluminum alloys. UK patent 223994, 1923.

[3] BOISIER, Grégory, Nadine PÉBĖRE, Catherine DRUEZ, Martine VILLATTE a Stéphane SUEL. FESEM and EIS Study of Sealed AA2024 T3 Anodized in Sulfuric Acid Electrolytes: Influence of Tartaric Acid. Journal of The Electrochemical Society [online]. 2008, 155(11) [cit. 2020-06-03]. DOI: 10.1149/1.2969277. ISSN 00134651. Available from: https://iopscience.iop.org/article/10.1149/1.2969277.

[4] GARCÍA-RUBIO, M., P. OCÓN, A. CLIMENT-FONT, et al. Influence of molybdate species on the tartaric acid/sulphuric acid anodic films grown on AA2024 T3 aerospace alloy: Influence of Tartaric Acid. Corrosion Science [online]. 2009, 51(9), 2034-2042 [cit. 2020-06-03]. DOI: 10.1016/j.corsci.2009.05.034. ISSN 0010938X. Available from: https://linkinghub.elsevier.com/retrieve/pii/S0010938X09002388

[5] MONTOYA Z, R D, E VERA L, Y PINEDA T, et al. Effect of the layer of anodized 7075-T6 aluminium corrosion properties: Influence of Tartaric Acid. Journal of Physics: Conference Series [online]. 2017, 786(9), $2034-2042$ [cit. 2020-06-03]. DOI: 10.1088/1742-6596/786/1/012032. ISSN 1742-6588. Available from: https://iopscience.iop.org/article/10.1088/1742-6596/786/1/012032 